\title{
HIGH-ACCURACY POSITION CONTROL SYSTEM FOR UNDERGROUND DIAPHRAGM WALLS
}

(Slurry Walls)

Masao Arai and Teiji Naitoh, Construction Technology Development Department, Taisei Corporation

$$
\begin{gathered}
\text { 1-25-1 Nishi-Shinjuku, Shinjuku-ku, } \\
\text { Tokyo, 163, Japan }
\end{gathered}
$$

\section{SUMMARY}

This paper describes a landmark High-Accuracy Position Control System for Underground Diaphragm Walls. The demand for ultra-large underground diaphragm walls, reaching the maximum depth of $170 \mathrm{~m}$ and thickness of $3.2 \mathrm{~m}$ has lately increased. This high-accuracy position control system for use in the construction of such underground diaphragm walls is the first practical system to be developed which is capable of controlling construction accuracy to within $50 \mathrm{~mm}$, an extremely difficult level of precision to reach.

\section{INTRODUCTION}

Remarkable technological innovation in the field of construction in recent years has increased the necessity for thick diaphragm walls deep underground, far exceeding the conventional limit of $1.2-1.5 \mathrm{~m}$ in wall thickness as $100 \mathrm{~m}$ in depth, as a way to make use of underground space on a large scale or as foundations for ultra-large structures and structures on soft ground.

There are presently some projects in waterfront developments and other areas where such ultra-large underground diaphragm walls are planned. They are the key to the multi-purpose utilization of underground space in urban areas, so the demand for greater and greater accuracy in this technology is increasing.

The accuracy of underground diaphragm wall construction depends mainly upon the accuracy of excavation, so a position control system able to reliably control excavation to an accuracy of several tens of millimeters at a great depth has been demanded. An accuracy control system using laser beams has already been developed, and its performance was confirmed through deep excavation verification tests.

Unfortunately, the laser system resulted in a loss of workability because setting up the laser pipe joints required a lot of work. In consequence, we set about developing a more workable system and have developed the "High-Accuracy Position Control system" which can control excavation to an accuracy of $50 \mathrm{~mm}$ of the maximum displacement during excavation. Such an accuracy would be extremely difficult conventionally. A control rack above ground is connected to the excavator with wires for detecting displacement: the displacement of the wire caused by excavator movement in units of microns using a laser displacement 
gauge, and the absolute position, torsion, inclination, and other characteristics of the excavator are displayed in real time on a monitor in the operation room. This highly accurate data is used to control the posture of the excavator.

The system has been used in the construction of underground diaphragm walls for the Hakucho Ohashi Bridge in Muroran City, Hokkaido $(1.5 \mathrm{~m}$ thick, $106 \mathrm{~m}$ deep; Photo 1), the Koto Pump Facility in Tokyo $(2.6 \mathrm{~m}$ thick, $104 \mathrm{~m}$ deep, Photo 2$)$, the Kawasaki Channel Tunnel in Kawasaki City $12.0 \mathrm{~m}$ thick, $80 \mathrm{~m}$ deep), and other projects, where it operated well with extremely good results.

\section{SUMMARY OF SYSTEM}

This "High Accuracy Position Control System" for underground diaphragm walls uses a number of wires mounted on the excavator to detect position as shown in Fig. 1. By measuring the movement of the wires in units of microns as excavation progresses using an accurate laser displacement gauge, the absolute position, torsion, and inclination of the excavator can be decided with high accuracy. These data are displayed in real time on a monitor in the excavator operation room. Using this information to control the posture of the excavator, an underground diaphragm wall can be constructed to an accuracy of $50 \mathrm{~mm}$ regardless of the depth of the work.

\section{MEASUREMENT PRINCIPLE}

The operational state of the accuracy control rack and the excavator is described in Fig. 2. The laser displacement gauge on the accuracy control rack measures the displacement of the detecting wires caused by excavator progress, while the inclination angle and depth $D$ of the excavator body are measured using the inclinometer on the excavator and the depth gauge. The actual excavation position at the center of the drum cutter is calculated using three-dimensional processing based on these data, and the excavated section is constantly displayed on the monitor in real time.

To ensure the reliability of these measurements, a separate device for detecting a control point is fitted to the accuracy control rack and by synchronizing the behavior of the control point with the excavator displacement measurements, a correction of the measured values. To improve the reliability of measured values, real-time processing decentralized, meaning that measurement timing is synchronized at each CPU and the average movement value of each is processed. This secures stable and highly accurate measured values.

\section{SYSTEM CONFIGURATION}

The High-Accuracy Position Control System consists of an accuracy control rack and a data processing and display device.

Accuracy control rack

The accuracy control rack, as shown in Photo 3 , consists of laser displacement gauges, top sheave, a tensioning device, a 
winch, a slide base, a wire for the control point, a protective tube, a control board, and a frame. Measurement begins by connecting the detecting wires to the excavator using a crane when the designated position on the guide wall during lowering of the excavator.

(2) Data processing and display device

The data processing device shown in Photo 4 consists of a display for displacement measurements, a computer for data processing operations, a data display device, a keyboard, a printer, audio device, etc. These are normally incorporated in a special rack placed near the excavation operator's seat for easy use.

\section{MEASUREMENT DISPLAY}

The excavation data are displayed on the monitor as described in Fig. 3. Details of the displayed values are given below.

(I) Horizontal displacement of cutter

This shows in which direction the plane position of the four corners of the drum cutter have slipped from the design position in the plane of excavation. The numerical values are the displacements of the four corners of the drum cutter in the $X$ and $\mathrm{Y}$ directions in centimeters.

Also, on the screen, the control frame in the design position is shown in blue, one slipped from the design position by $30 \mathrm{~mm}$ in yellow, and one off the design position by $50 \mathrm{~mm}$ in red. This enables the operator to keep excavator within the control frame in red without having to read displacement values from the screen.

\section{(2) Messages}

Comment about operations and instruction if it is necessary to correct the position in case the excavator goes out of the control frame, etc., are displayed on the screen and given audibly.

\section{(3) Inclination of excavator}

The inclination state of the excavator to right and left, and front and rear, is displayed on the screen.

(4) Hysteresis record of the center of the excavator

The hysteresis in displacement between the design position in the $X, Y$ directions and the center of the excavation trench while excavating is displayed.

(5) Cutter data

1 Current excavation speed: $\mathrm{cm} / \mathrm{min}$

2 Current excavation depth: m 
3 Current displacement in

$\mathrm{X}$ direction : $\triangle \mathrm{X} \mathrm{cm}$

4 Current displacement in

$\mathrm{Y}$ direction : $\triangle \mathrm{Y} \mathrm{cm}$

5 Current torsion angle of

excavator : deg.

6. FEATURES OF HIGH-ACCURACY POSITION CONTROL SYSTEM

(1) Continuous position control of excavator.

(2) Real-time detection of absolute position of excavator.

(3) Control of excavator posture by the operator without delay by referring to the monitor.

(4) Position detection fully automatic, so no interference with other operations.

(5) Excavation accuracy to within $50 \mathrm{~mm}$ regardless of excavation depth.

(6) Even vibration of ground and measurement devices does not interfere, since the system has a correction device for the control point.

(7) The completed shape of the excavated trench is displayed on the monitor, so ultrasonic trench wall measurements are unnecessary during excavation.

(8) Position detection system works to a depth of $200 \mathrm{~m}$ or less.

(9) Equipment is small and light, so transport and movement is easy.

7. ACTUAL MEASUREMENTS WITH HIGH-ACCURACY POSITION CONTROL SYSTEM

A comparison of control data taken during excavation with the high-accuracy position control system and data measured by an ultrasonic trench wall measurement device after the completion of excavation is shown in Fig. 4.

The two sets of data are in good agreement, verifying that the new system is very suitable for the accuracy control of underground diaphragm walls.

8. CONCLUSION

This high-accuracy position control system was developed for use in constructing thick diaphragm walls deep underground with high accuracy. Adoption of the system has made it possible to control the maximum displacement to within $50 \mathrm{~mm}$ even in the case of underground diaphragm walls at a depth exceeding $100 \mathrm{~m}$. Although the system has been used for multishaft excavators, its use with a vertical multishaft excavator and a reverse excavator has also been proven. 


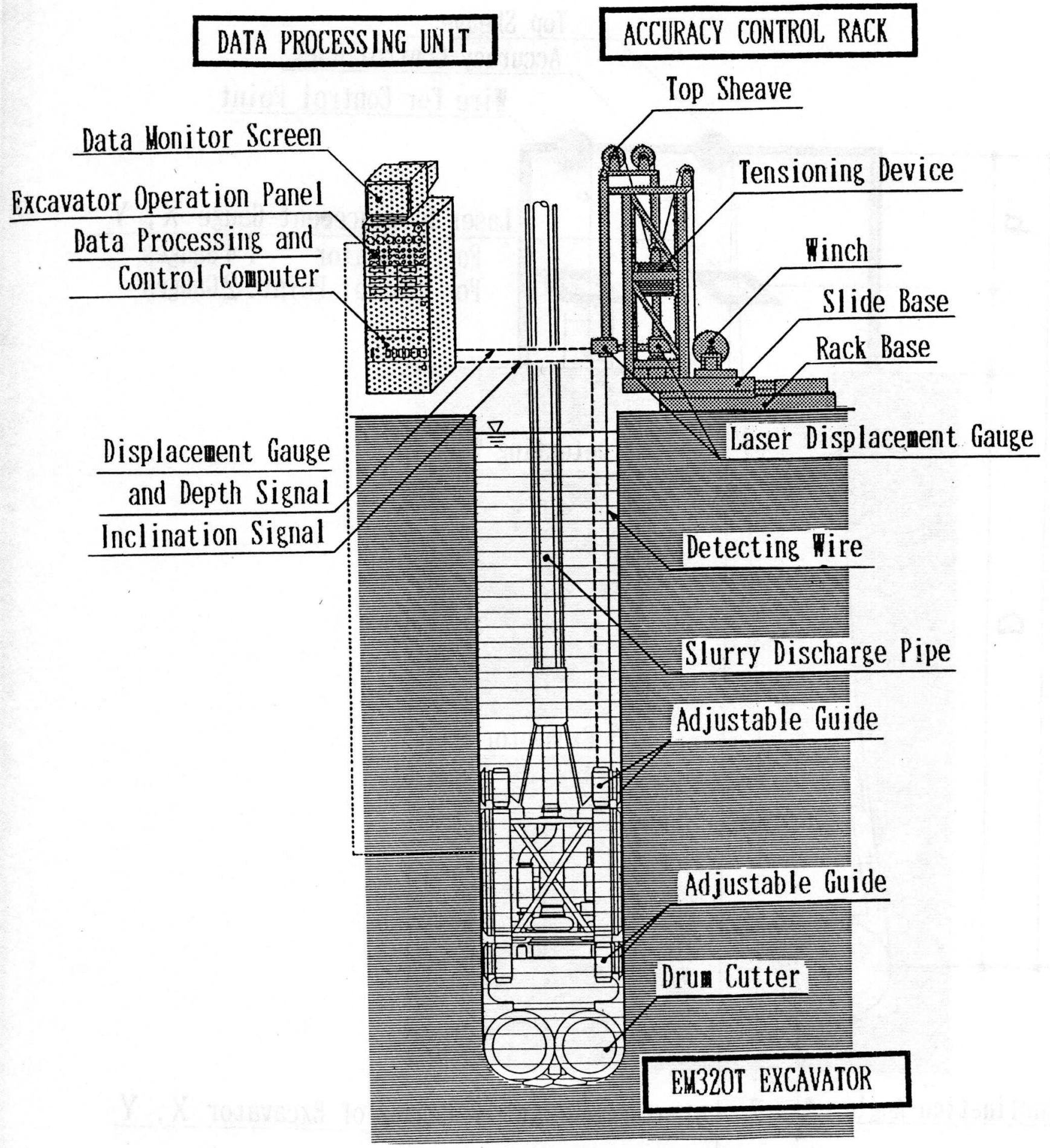

Fig. 1 Summary of High-Accuracy Position control System 


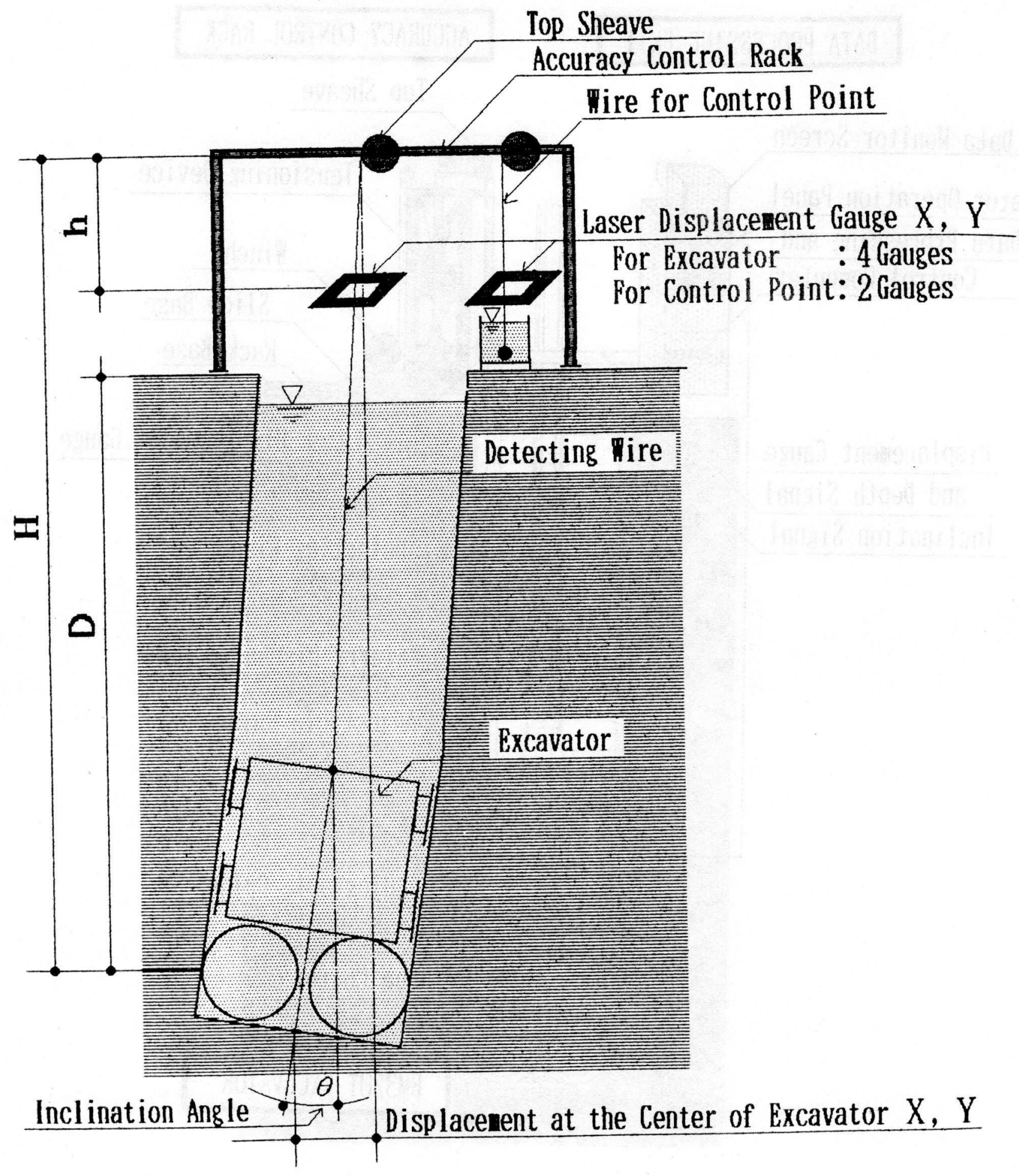

Fig. 2 Principle of measurement 
【 HIGH-ACCURACY POSITION CONTROL SYSTEM 】
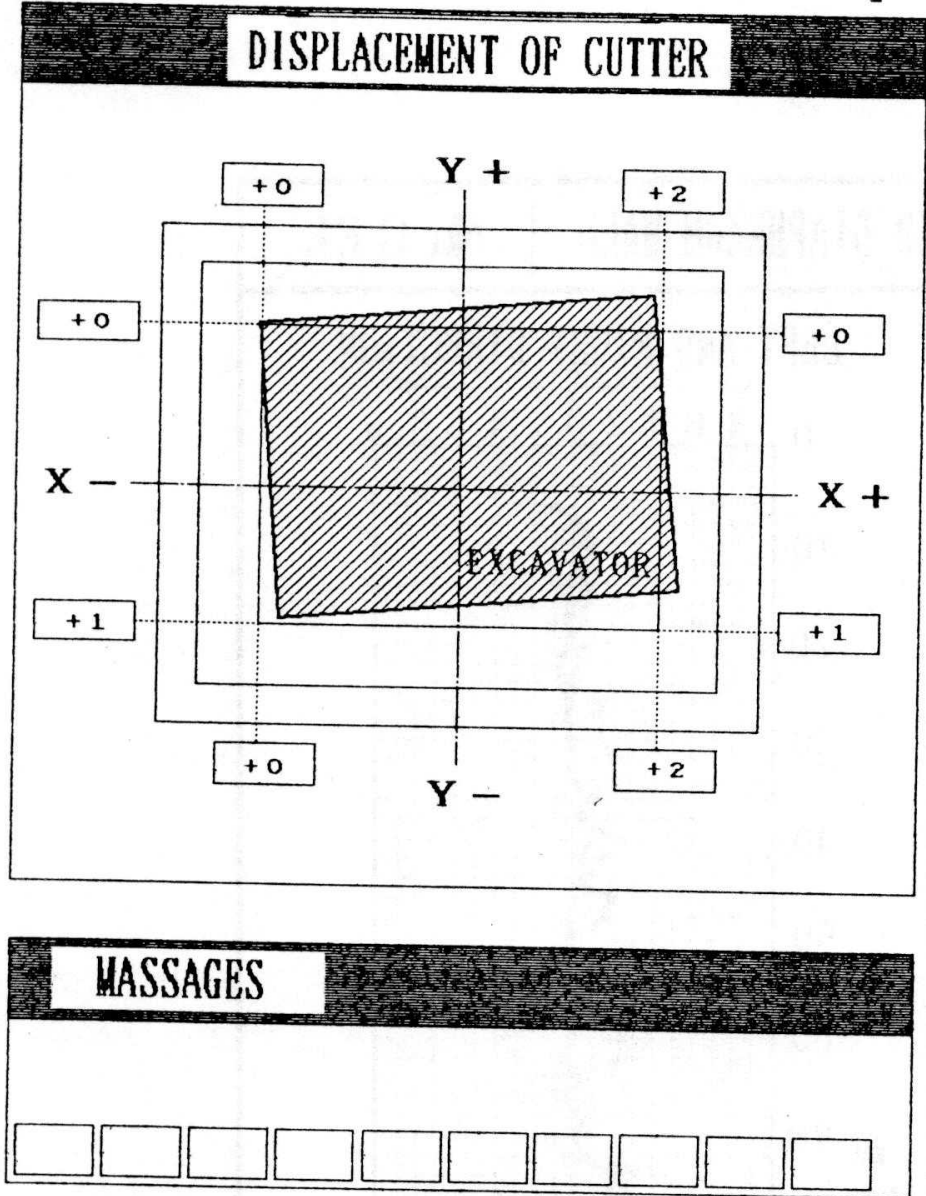

DISPLACEMENT OF CENTER

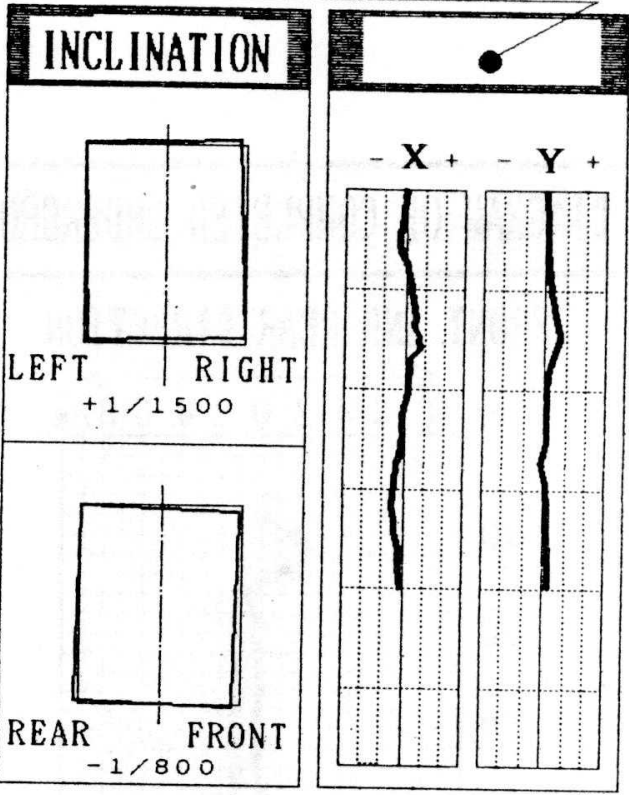

\section{CUTTER DATA}

EXCAVATION SPEED $\mathbf{V}=\mathrm{cm} / \mathrm{m}$ in

D E P T H $\quad \mathbf{L}=$ H

CENTER $\quad \boldsymbol{\Delta} \mathrm{X}=\mathrm{cm}$

DISPLACEMENT $\boldsymbol{\Delta} \mathrm{Y}=\mathrm{c} \mathbb{\mathrm { I }}$

TORSION ANGLE $\boldsymbol{\Delta} \theta=\mathrm{deg}$

Fig. 3 Display 


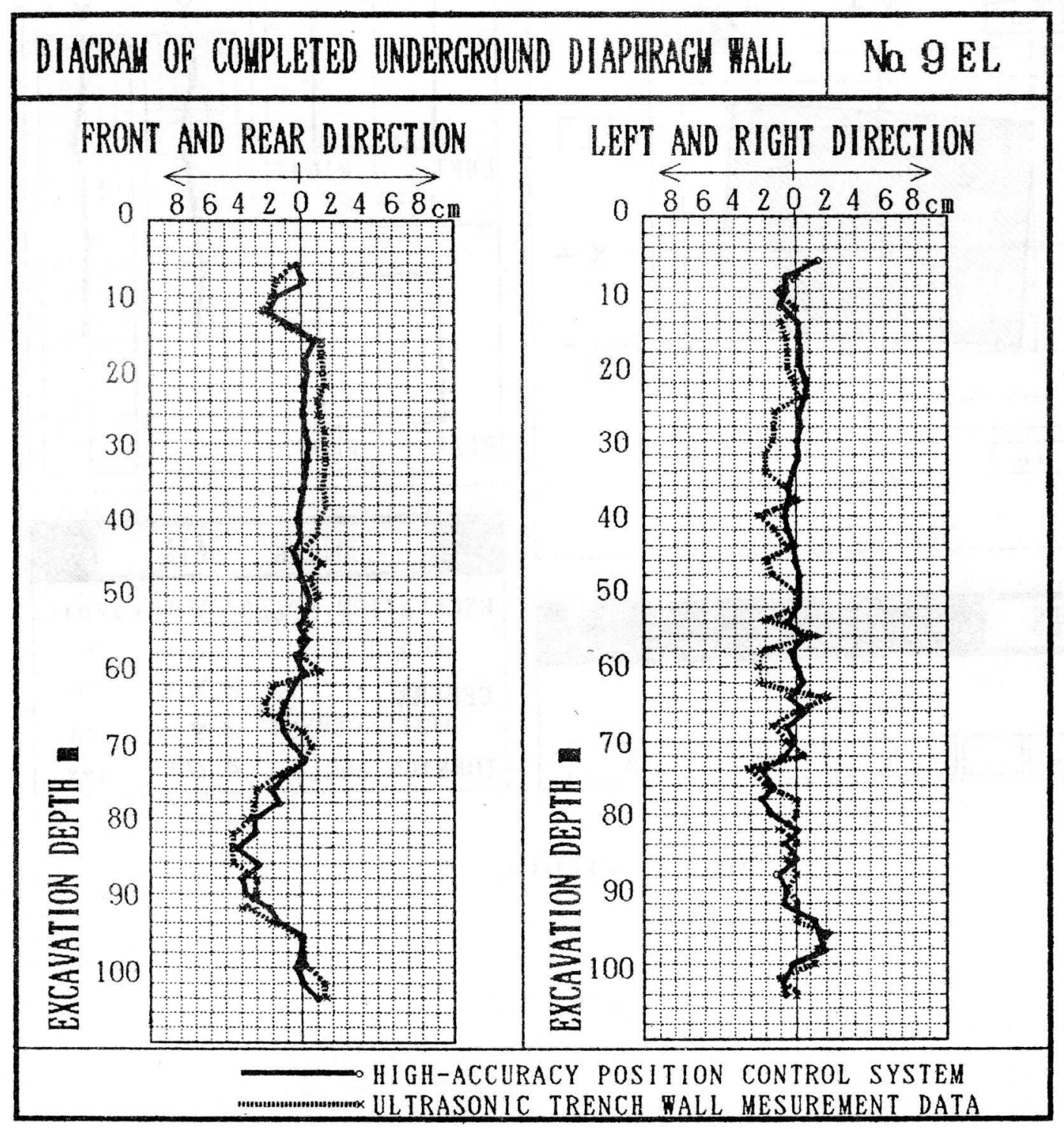

Fig. 4 Data comparison 


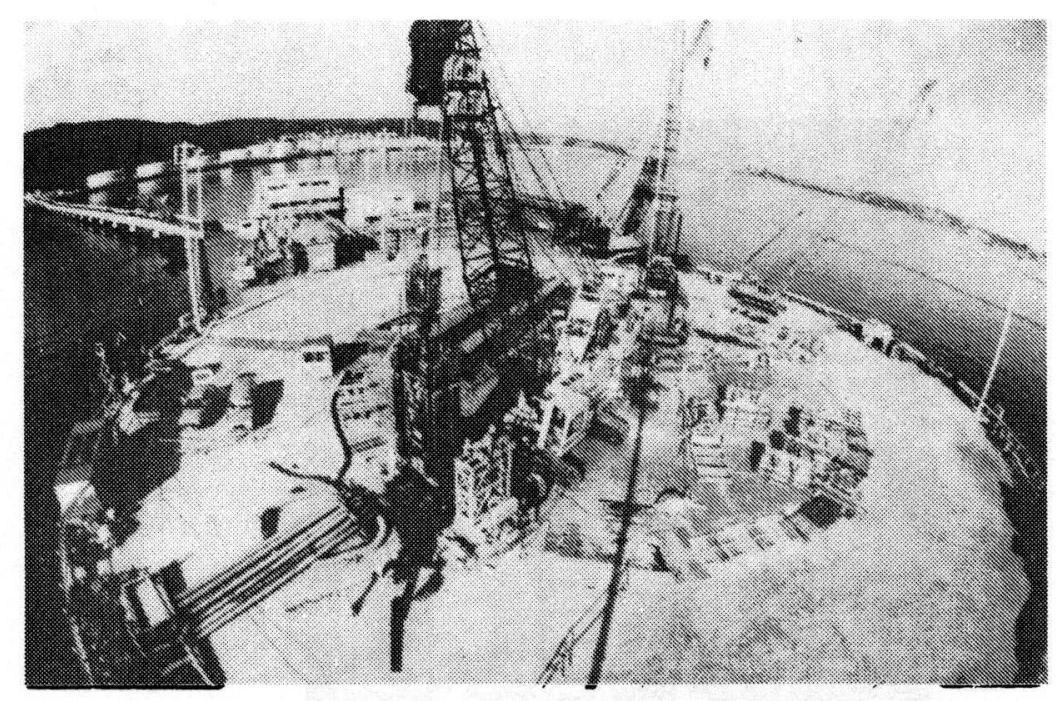

Photo 1 Application of the accuracy control system (Hakucho Ohashi Bridge - Hokkaido Development Bureau)

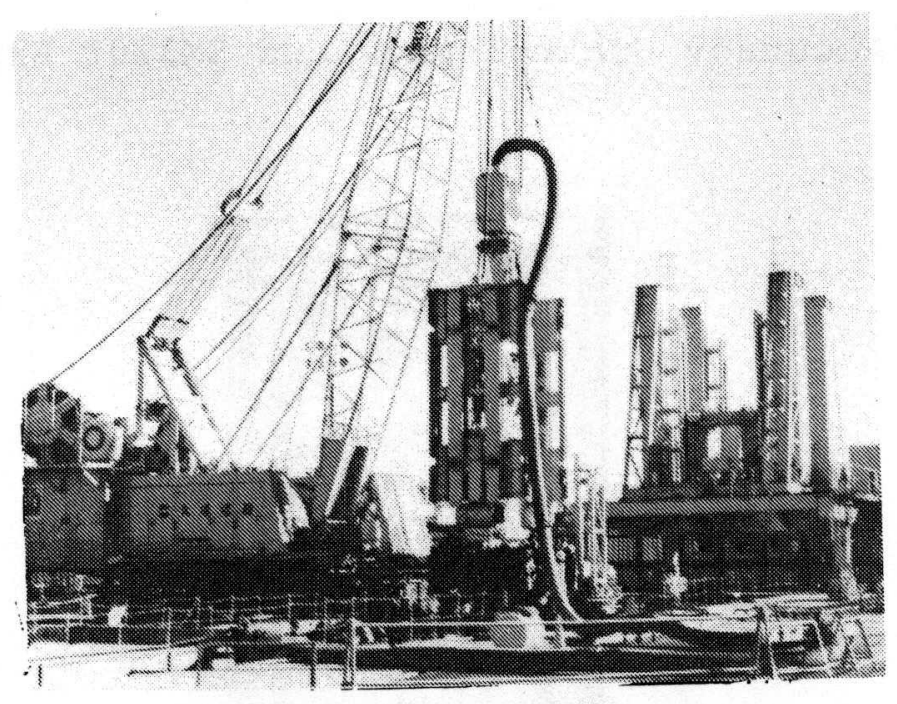

Photo 2 Application of the accuracy control system (Koto Pump Facility - Sewerage Bureau, Tokyo Metropolitan Government) 


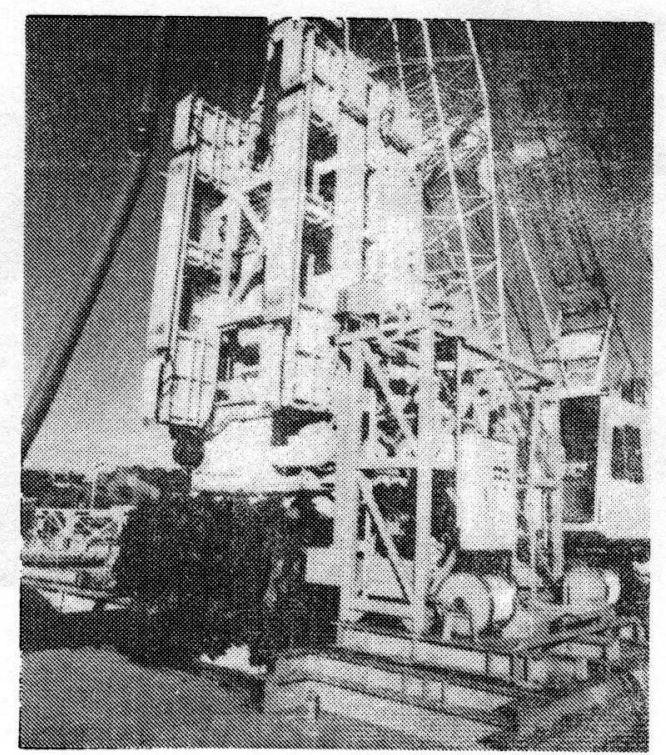

Photo 3 Accuracy Control Rack and EM320T Excavator

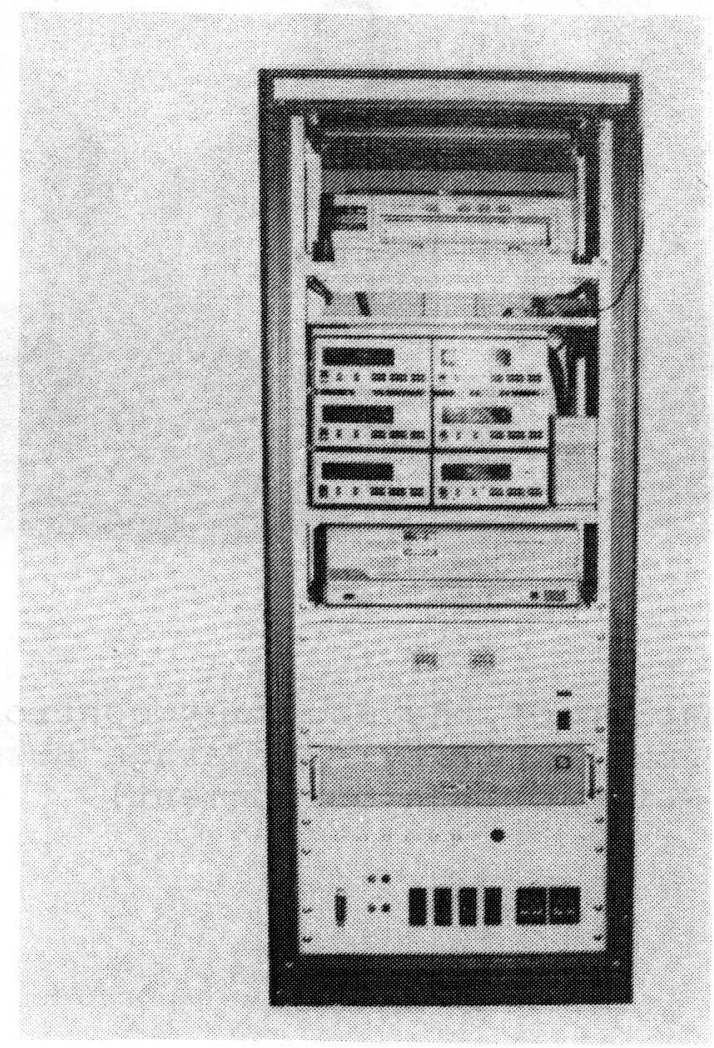

Photo 4 Data Processing and Display Device 